\title{
ICT IN LIFE OF STUDENTS AT THE LATVIA UNIVERSITY OF LIFE SCIENCES AND TECHNOLOGIES
}

\author{
Anda Zeidmane \\ Latvia University of Life Sciences and Technologies, Latvia \\ anda.zeidmane@1lu.lv
}

\begin{abstract}
Information and communication technology (ICT) plays an important role in our daily activities. ICT can have positive and negative impacts on organizations, people and society. Rapid access to information, improved access to education, new job opportunities, new tools etc. may be mentioned as a positive impact of ICT on people, but the decrease in personal interaction and the decline in physical activity may be mentioned as negative aspects of ICT. Also, the impact of ICT on society is both positive, such as improved communication across the world, increasing educational opportunities, and negative, such as the digital divide between those who have access to information and who cannot have, as well as the availability of a large number of incorrect and misleading information. Students spend a lot of their time using the ICT or the Internet facilities. The objectives of the study are: i) to explore how and how much of their time students spend by using ICT; ii) to find out the relationship between students' use of ICT for an academic and non-academic purpose and their performance; iii) to identify which educational software students know and use. In order to achieve the objectives of this study, more than 150 second-year students of the Latvia University of Life Sciences and Technologies were surveyed. The first part of the questionnaire focused on students' time distribution per week. The results of the study show that the students of LLU spend using ITC for more than $25 \%$ of the time per week, about $30 \%$ of the time is devoted to sleeping and rest, about $20 \%$-to learning. The second part of the questionnaire focused on exploring how much time students spend for academic, non-academic and social use of ICT. The results show that about $63 \%$ of the time spent on the Internet is used for non-academic purposes. The third part of the questionnaire provided information on students' knowledge, skills and habits to use different educational software. The study suggests that proper steps should be taken by the academic or related institutions to promote the use of ICT for focusing on academic purposes, so that the students may benefit more from using ICT.
\end{abstract}

Keywords: students, academic use of ICT, non-academic use of ICT, educational software.

\section{Introduction}

Information and communication technology (ICT) combines both traditional computer-based technologies and modern digital communication technologies. Computer-based technologies include standard Office applications, as well as various computer programs that help companies do business. Digital communication is the process of electronic storage, receipt and exchange of information electronically. The scope of ICT is used in a variety of contexts, including economic development, economic sector, education, IT, business and personal use [1]. If the use of ICT in the economic sector and business is more relevant to the studens future professional activity, the effective use of ICT in education requires a certain level of competence. The students are spending a lot of their time using the ICT or Internet facilities. The question arises: is it good or bad?

ICT can have positive and negative impacts on people, organizations, and society [2].

The following factors may have a positive impact on people:

- Access to information (such as instant messaging, new opportunities for leisure and entertainment, facility to make contacts with people around the world, ability to obtain goods and services from a wider range of suppliers);

- Improved access to education and new job opportunities (such as distance learning and online tutorials, new ways of learning, new job opportunities);

- New tools, new opportunities (such as photo-editing software and high quality printers or help people overcome disabilities).

The following factors may have a negative impact on people:

- Job loss (manual operations being replaced by automation);

- Reduced personal interaction (people do not get the chance to meet and talk with other people, they may feel isolated and unhappy);

- Reduced physical activity (this can lead to health problems, such as obesity, heart disease, and diabetes). 
Using ICT in organizations has produced a number of advantages in communication and information management. E-mail, video conferencing, bank transfers that are widely used, access to markets worldwide and improvement of the supply chain of goods and services can be mentioned as positive impacts in communication. Organisations can benefit from using ICT for information management, such as acquiring customer information data and improved stock control. As negative impacts on organization can be mentioned hardware and software costs and maintenance, requires specialist staff as well as increased competition between companies. A big problem for any organization using ICT is security.

The largest impact of the use of ICT on society is that members of society can significantly increase the access to information promoting educational opportunities. The impact of ICT on education is both positive and negative. E-learning is one of the main positive aspects of ICT in education. E-learning eliminates the linear constraints of traditional curricula. The teaching and learning process can take place in training centres, houses and even remote areas [3]. Users can learn the training programme at their own pace. The positive impact of ICT is also the acquisition of competences, such as critical thinking and collaboration [4]. Technology has been shown to positively influence student learning when students explore technology rich tasks, which at the same time require them to use higher order thinking skills as analysis and evaluation of information, creation of new knowledge representation [5]. ICTs can promote lifelong independent learning skills. ICT offers learners' tasks that are better suited to individual needs, makes it easier to organize their own learning, which increases student responsibility for their own learning [6].

However, the positive impact of using ICT in education has not been proven. ICT is considered to be less effective (or ineffective), if the goals for their use are not clear [7,8]. In general, education productivity is difficult to define for the education sector, as output is not easy to measure. Educational technologies should influence educational outcomes and costs [9].

In spite of the above, ICT has become one of the most used means of communication by university students and they spend a lot of time on it. This raises many questions that are important for both teachers and students, for example:

- how much time students spend using computers and smartphones;

- what are the purposes of using the Internet [10];

- whether there is a correlation between academic use of ICT, non-academic and social use of ICT, ICT addiction and students' performance [11];

- whether students know and use educational software to improve the educational process.

Many educational applications have been developed, but according to PC World 2017 data, the top ten are [12]:

- One Note - snip and save articles, share notebooks with a group;

- Microsoft To-Do - plan your day with intelligent suggestions;

- Polarr - advanced tools for more sophisticated work on a photo;

- Edmodo - allowing to post assignments, videos, or other key content into one site that everyone can find;

- GeoGebra - assists in graphing, geometry, algebra and other;

- Nebo - transcribes your writing in real-time, performing math equations and adding images;

- Sensavis - interactive digital teaching aids, visual models;

- Fluid Math - convert your handwriting into formulas and allow you to graph solutions on the digital paper;

- One Calendar - integrate all your calendars into an easy-to-read overview;

- Khan Academy - provides visual assistance for spicing up a presentation.

Objectives of the study are:

- to explore the time distribution of the students of the University of Life Sciences and Technologies per week to find out how and how much of their time students spend by using ICT. 
- to find out the relationship between the students' use of ICT for academic and non-academic purpose and their performance.

- to identify which educational software the students know and use.

\section{Materials and methods}

Primary sources of information were used to achieve the objectives of this study. Primary data were taken from the respondents using a close ended questionnaire. The sample size of the study was chosen from the second year students of the University of Life Sciences and Technologies (LLU). A sample size consisted of 150 students (the principle of an occasional selection) from the Faculty of Information Technology, Faculty of Engineering, Faculty of Food Technology and foreign students from the Faculty of Information Technology.

The questionnaire was designed with closed questions including ranged answers. The questionnaire was divided into three main areas. The first part of the questionnaire was focused on the students' time distribution per week to find out how much time the students spend using ICT, learning and what their other activities are. The second part of the questionnaire focused on exploring how much time the students use ICT for academic purposes, communicating in social networks and entertainment as well as to find out their specific interests in the use of ICT. The third part of the questionnaire provided information on the students' knowledge, skills and habits to use different educational software.

The application software Microsoft Excel was used in order to process the quantitative research data, to perform statistical analysis and to visualize the results. Software package IBM SPSS was used for correlation analysis with the Spearman' coefficient.

\section{Results and discussion}

The analysis of the first survey results shows that that most of the time students spend using ICT $(25.4 \%) \quad($ mode $=$ median $=$ "partly"), sleeping and resting $(29.9 \%) \quad($ mode $=$ median $=$ "partly" $)$, Fig. 1.

The comparison of the results by the faculties shows that students from the Faculty of Information Technology use ICT a little more $(27.0 \%)$ (mode = median = "partly"), but students from the Faculty of Food Technology use the least $(21.4 \%)$ (mode = median = "partly"), because in this faculty the proportion of girls is much higher than in the engineering faculties. The fact that students from the the Faculty of Food Technology spend more time for learning (in contact lessons and independently) $(21.3 \%)($ mode $=$ median $=$ "partly") also shows that girls are a little more diligent than boys.

The correlation analysis shows that there is a positive correlation between the students' performance and additional work $\left(\mathrm{r}_{\mathrm{Sp}}=0.46, \mathrm{p}=0.01\right)$ as well as sport and other activities $\left(r_{S p}=0.51\right.$, $p=0.01$ ), which shows that active students can manage their time and show good results in the learning process.

The results of the second survey show that students use ICT mostly for non-academic purposes (communicating in social networks and entertainment), Table 1. Students from the Faculty of Food Technology (mostly girls) spend more time on communicating in social networks $(30.8 \%)$ ( mode $=$ median $=$ "partly"), while engineering faculties' students (mostly boys) spend more time in entertainment $(52.3 \%$ and $47.1 \%)($ mode $=$ median $=$ "partly").

Time distribution of using the Internet of students of the

Table 1

\section{Latvia University of Life Sciences and Technologies (LLU)}

\begin{tabular}{|c|c|c|c|c|}
\hline Activity & $\begin{array}{c}\text { Students of the } \\
\text { Faculty of } \\
\text { Engineering }\end{array}$ & $\begin{array}{c}\text { Students of the } \\
\text { Faculty of } \\
\text { Information } \\
\text { Technology }\end{array}$ & $\begin{array}{c}\text { Students of the } \\
\text { Faculty of Food } \\
\text { Technology }\end{array}$ & $\begin{array}{c}\text { Foreign students } \\
\text { of the Faculty of } \\
\text { Information } \\
\text { Technology }\end{array}$ \\
\hline Academic use of ICT & $31.4 \%$ & $38.4 \%$ & $32.5 \%$ & $38.4 \%$ \\
\hline $\begin{array}{c}\text { Communicating in } \\
\text { Social Networks }\end{array}$ & $16.3 \%$ & $14.5 \%$ & $30.8 \%$ & $14.5 \%$ \\
\hline Entertainment & $52.3 \%$ & $47.1 \%$ & $36.7 \%$ & $47.1 \%$ \\
\hline
\end{tabular}




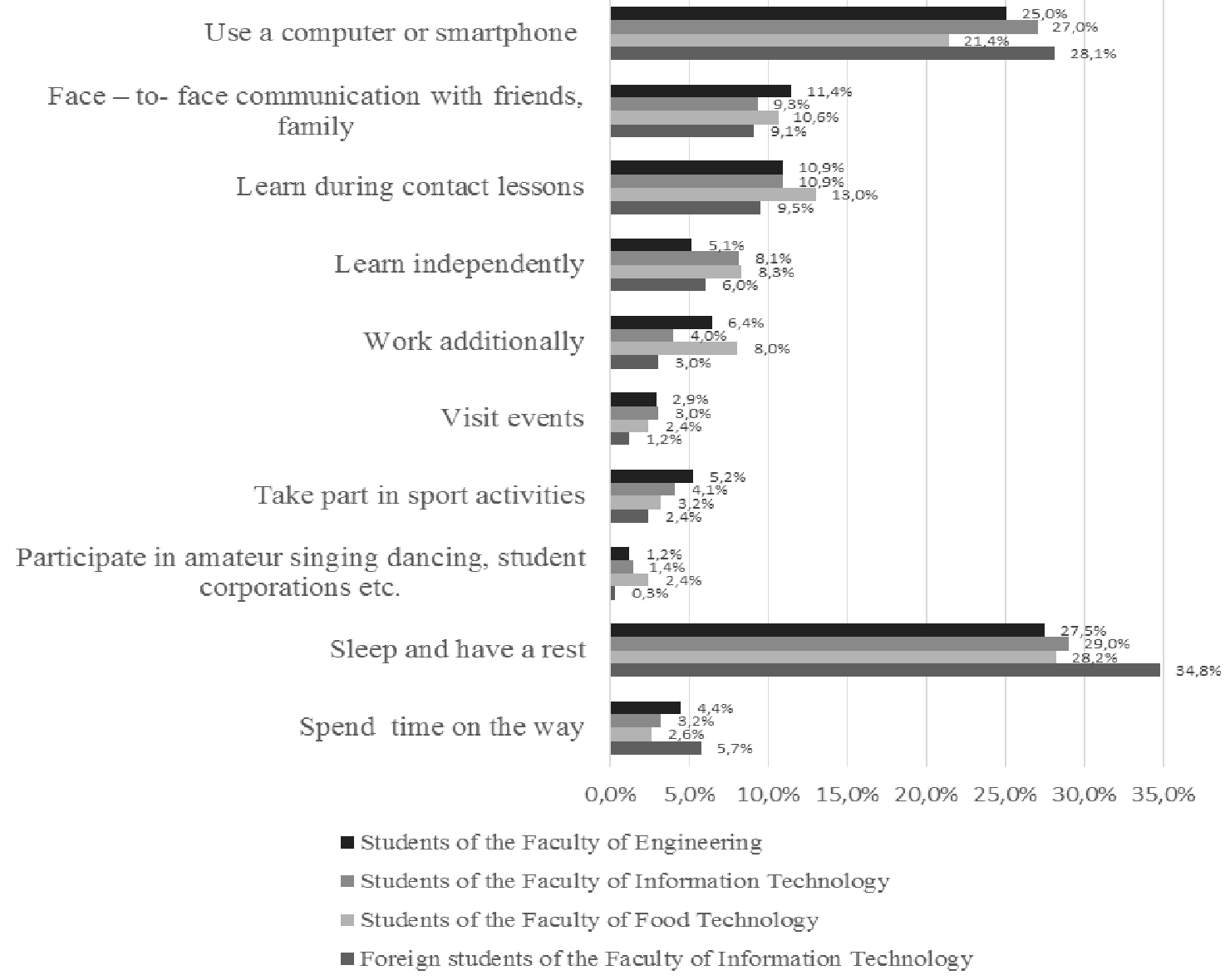

Fig. 1. Time distribution of students of the Faculty of Engineering, Faculty of Information Technology, Faculty of Food Technology and foreign students Faculty of Information Technology per week

Analysing the use of ICT for academic purposes, Fig. 2, it may be concluded that students mostly use the Internet for searching specific information (regularly $-30.8 \%$, often $50.8 \%)$, (mode =median $=$ "partly"), quite often they use E-learning tools (regularly and often $57.7 \%$ ), but $71.2 \%$ do not use ebooks at all.

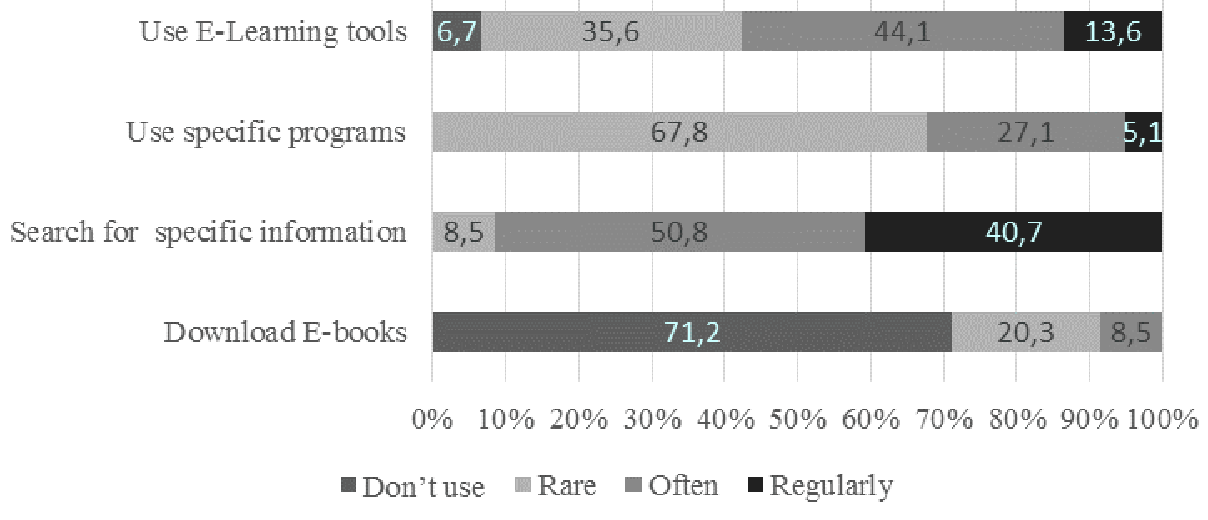

Fig. 2. Purposes and frequency of academic use of ICT of students of LLU

Relating to the use of ICT for entertainment, Fig. 3, the results show that most of the students browse the Internet (regularly and often $-93.2 \%)($ mode $=$ median $=$ "partly") and use YouTube (regularly and often $-93.2 \%$ ), which may cause ICT addiction and negatively affect the student performance. Computer games are not a problem for our students.

E-mail, calendars, maps and shopping are the most popular mobile devices that students have mentioned in the questionnaires that help in everyday life, Fig. 4. 


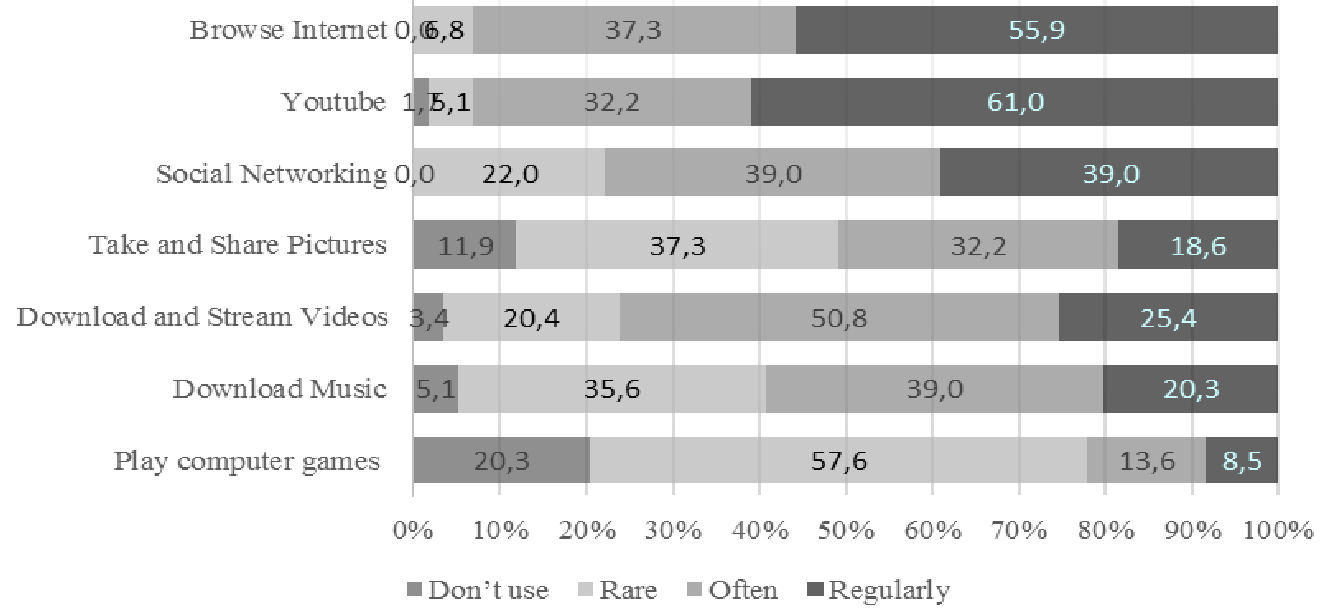

Fig. 3. Purposes and frequency of using the Internet for entertainment of students of LLU

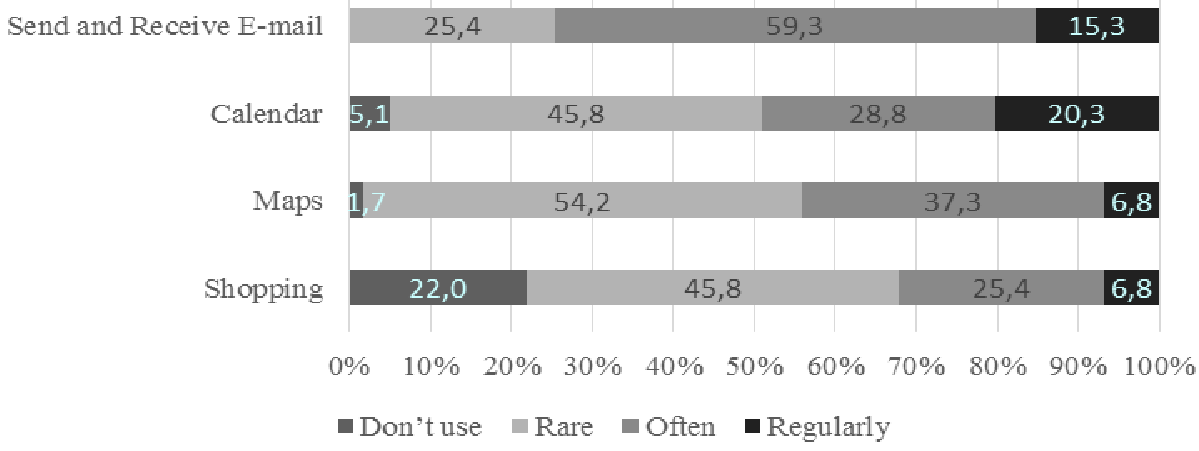

Fig. 4. Purposes and frequency of using the Internet for everyday needs of students of LLU

As mentioned above, PC World 2017 data are recognized by ten top educational softwares for students. The results show that students have not even heard of most of the recommended educational softwares, Fig. 5. Most often students use One Calendar $(16.9 \%)($ mode $=$ median = "partly") that helps integrate all your calendars into an easy-to-read overview and One Note $(15.3 \%)$ $($ mode $=$ median $=$ "partly") that helps snip and save articles and share notebooks within a group .

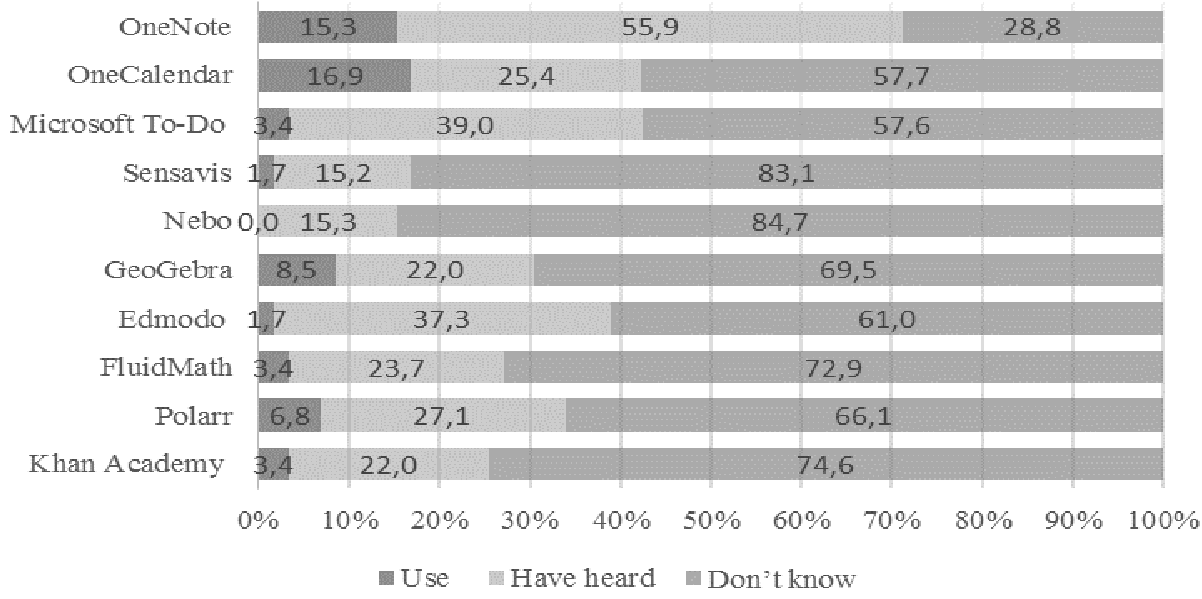

Fig. 5. LLU students' ability to use most popular educational software to improve their educational process

It is a sad fact that students almost do not use educational software like Sensavis that offers indepth instruction for a ton of different science subjects. Sensavis delivers interactive digital learning tools and visual models for activate learning. 


\section{Conclusions}

1. The results of the study show that the students of LLU spend using ITC for more than $25 \%$ of the time per week, about $30 \%$ of the time is devoted to sleeping and rest, about $20 \%$-to learning, but the rest of the time is devoted to other activities.

2. Students use ICT mostly for non-academic purposes, mainly for communicating in social networks and entertainment (about $63 \%$ of the time spent on the Internet). Using ICT for academic purposes, students prefer to use the Internet for searching specific information rather than using E-learning tools or specific programs.

3. As for the use of educational software in the learning process, the students have not even heard of most of them. Academic institutions must have a sufficient support to familiarize students with the latest educational software and to promote the use of ICT for academic purposes.

4. In the time when technology plays an important role in our daily activities, including in the academic arena, it is important to assess the impact of ICT in the students' life and ensure its positive use as much as possible.

\section{References}

[1] Zuppo C.M. Defining ICT in boundary less world: the development of a working hierarchy. International Journal of Managing Information Technology (IJMIT) Vol.4, No.3, August 2012. [online] [01.02.2019]. Available at: http://airccse.org/journal/ijmit/papers/4312ijmit02.pdf

[2] Adewunmi A., A., Olayinka A.E., Zainab A., A. etc. The positive and negative impacts of ICT. Ajahana. Another WordPress.com site. Posted on June 2012. [online] [07.01.2019]. Available at: https://ajahana.wordpress.com/2012/06/27/the-positive-and-negative-impacts-of-ict-5/

[3] Sridevi J., Krishnan B.,.Senthil K. Information and Communication Technology (ICT) in Higher Education: Advantages, Disadvantages OF Applying E-Learning to Students. International Journal of Pure and Applied Mathematics, Volume 117 No. 15 2017, pp. 177-182

[4] Leu D. J., McVerry J., G., O’Bryne W. etc. The New Literacies of Online Reading Comprehension: Expanding the Literacy and Learning Curriculum. Journal of Adolescent and Adult Literacy. Vol.55, No1, Sept 2011.

[5] Polly D. Developing Students' Higher-Order Thinking Skills (HOTS) through Technology-Rich Tasks: The Influence of Technological Pedagogical and Content Knowledge (TPACK). Educational Technology, Vol.51, No 4, Jul-Aug 2011, pp. 20-26.

[6] Balanskat A., Blamire R. and Kefala S. The ICT Impact Report: A review of studies of ICT impact on schools in Europe. European Schoolnet, 11 Dec 2006. 75p. [online] [09.01.2019]. Available at: http://edz.bib.uni-mannheim.de/daten/edz-b/gdbk/06/ict_impact_report.pdf

[7] Impact of ICTs on Learning \& Achievement. A Knowledge Map on Information \& Communication Technologies in Education. [online] [09.01.2019]. Available at: http://www.infodev.org/articles/impact-icts-learning-achievement

[8] Kumar A., S. Kedar S. Impact of ICT on students learning achievement and motivation-some debatable issues. Proceedings of $8^{\text {th }}$ International Technology, Education and Development Conference, March 10-12, 2014, Valencia, Spain, pp. 7404-7409

[9] Nwigbo S.,,Madhu B.,K., Impact of ICT on the Teaching and Learning Process. IOSR Journal of Mobile Computing \& Application (IOSR-JMCA), Vol. 3, No 2, Mar.-Apr. 2016. [online] [14.01.2019]. Available at: http://iosrjournals.org/iosr-jmca/papers/Vol3-issue2/A03020107.pdf

[10] Megan K. F, Mendez J., Mobile Learning: How Students Use Mobile Devices to Support Learning. Journal of Literacy and Technology. Vol. 15, No 3, December 2014, pp. 58- 78.

[11] Talukder S., Alam J., Apu A.,I., the impact of ICT on students' performance: a case study on undergraduate university students. Manarat International University Studies, Vol.4, No 1, 2015. pp. 137-147.

[12] Derek W. The best educational software for students PC World from IDG, Aug 17, 2017. [online] [09.12.2018]. Available at: https://www.pcworld.com/article/3214486/software/the-besteducational-software-for-students.html 